\title{
A neural network approach for the on-line estimation of workpiece height in WEDM
}

\author{
Y.S. Liao ${ }^{\mathrm{a}}$, M.T. Yan ${ }^{\mathrm{b}}$, , C.C. Chang ${ }^{\mathrm{a}}$ \\ ${ }^{a}$ Department of Mechanical Engineering, National Taiwan University, No. 1, Roovevelt Road, Sec. 4, Taipei 106, Taiwan, ROC \\ ${ }^{\mathrm{b}}$ Department of Mechanical Engineering, Huafan University, No. 1, Huafan Road, Shihtin Hsiang, 223 Taipei Hsien, Taiwan, ROC
}

Received 23 December 2000

\begin{abstract}
In this paper, a feed-forward neural network is used to estimate the workpiece height and distinguish the machining condition in wire electrical discharge machining (WEDM). Some experiments have been carried out to verify the effectiveness of this approach. Based on the on-line estimated workpiece height, a rule-based strategy is proposed to maintain optimal and stable machining. According to the rule-based strategy, servo voltage and power settings can be adjusted correctly to suit the workpiece profile. Experimental results demonstrate that high machining efficiency and stable machining can be achieved by means of the rule-based control strategy. (C) 2002 Elsevier Science B.V. All rights reserved.
\end{abstract}

Keywords: Wire electrical discharge machining; Neural network; Estimation; Workpiece height

\section{Introduction}

Wire breakage and unstable machining are the largest factors in the reduction of machining efficiency for the wire electrical discharge machining (WEDM) process, particularly when cutting a workpiece with a step shape. A conservative machining setting suitable for the thickness of the thinnest portion of a workpiece is often used to reduce the possibility of wire rupture and maintain a stable machining. However, the machining speed is greatly reduced. Therefore, there occurs a problem in that it is difficult to obtain the thickness of a workpiece real-time as machining progresses and set correct machining parameters to suit the workpiece profile with an unmanned operation system. Several approximate mathematical modes have been addressed in WEDM patents to estimate the thickness of the workpiece [1-3]. In essence, these mathematical equations represent the relationship between sparking energy and material removal rate, and the models' parameters are obtained by a large amount of experimental study. However, these static mathematical models are only suitable for the condition of cutting a workpiece with a gradual change in thickness. Due to the slow response speed, they may not adapt for the conditions of cutting a workpiece with a

\footnotetext{
${ }^{*}$ Corresponding author. Tel.: +886-2-2663-2102x4027; fax: +886-2-2663-2102x4013.

E-mail addresses: liaoys@ccms.ntu.edu.tw (Y.S. Liao), mtyan@huafan.hfu.edu.tw (M.T. Yan).
}

sudden decrease and increase in height. A multi-input model has been proposed to describe the dynamic and stochastic relationships between average gap feedback voltage and sparking frequency and machine table feed rate [4,5]. The proposed model can correctly and promptly estimate the workpiece height for an iso-frequency power generator. Nevertheless, the model's parameters rely heavily on the machining conditions, a great number of experiments and statistical techniques being required to derive the explicit mathematical model. However, the WEDM process involves a complex and time-varying process due to a large number of variables and the stochastic nature of the discharge mechanisms. Noisy electrode-workpiece gap voltage and gap current signals with some degree of uncertainty and vagueness are unavoidable. As a result, it is still not easy to describe the WEDM process by an explicit mathematical model. In this paper, a feed-forward neural network has been proposed to provide an on-line estimate of the workpiece height. Artificial neural networks have been implemented in various manufacturing fields such as tool breakage monitoring, inverse modeling of the cutting process and monitoring of the machining process $[6,7]$. Recently, the neural network approach has also been successfully applied to the modeling of the WEDM process and the online monitoring of the EDM process [8-10].

In Section 2 of this paper, a brief review of feed-forward neural networks with the back-propagation learning algorithm is described. The hardware set-up of a WEDM sparking frequency monitoring and control system is described in 
Section 3. A neural network approach for estimating the thickness of a workpiece is introduced briefly in Section 4. Experimental verification of the developed network and a strategy for optimal machining settings are discussed in Section 5. In Section 6, the paper concludes with a summary of this study.

\section{Description of a feed-forward neural network}

A feed-forward neural network is adopted here to estimate the thickness of a workpiece. The feed-forward neural network is composed of many inter-connected processing elements, called neurons or nodes, which operate in parallel, and can be grouped into input, hidden and output layers. The outputs of nodes in one layer are transmitted to nodes in another layer through connections that amplify or attenuate the outputs through weight factors. As shown in Fig. 1, an artificial neuron is divided into two parts: a summation function and an activation function. The summation function for all of the inputs is calculated by:

$\operatorname{net}_{j}^{n}=\sum_{i} W_{j i} O_{i}^{n-1}-\theta_{j}^{n}$

where net ${ }_{j}^{n}$ is the summation function of the $j$ th neuron in the $n$th layer, $W_{j i}$ the weight from the $i$ th neuron in the $(n-1)$ th layer, $O_{i}^{n-1}$ the output of the $i$ th neuron in the $(n-1)$ th layer and $\theta_{j}^{n}$ the threshold value of the $j$ th neuron in the $n$th layer. The neuron performs non-linear mapping of the result of the summation function through its activation function and then determines the output. The output of the neuron is transmitted along the outgoing connections to serve as an input to subsequent neurons. In the present study, a sigmoid function is used as the activation function. The output of the $j$ th neuron for the $n$th layer can be expressed as

$O_{j}^{n}=f\left(\operatorname{net}_{j}^{n}\right)=\frac{1}{1+\mathrm{e}^{\text {net }_{j}^{n}}}$

Before the input signals are transmitted to the input layer of the neural network, a scale mapping is performed to transfer the range of values of input variables into a corresponding

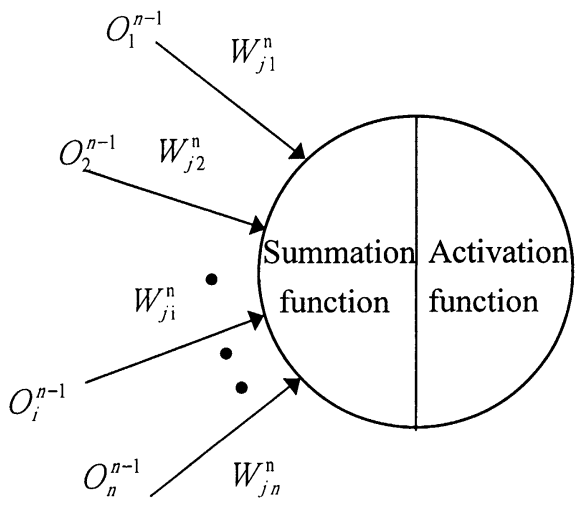

Fig. 1. An artificial neuron. universe of discourse. The scaling process prevents large value of input variables from dominating the training of the networks. As a result, all the input variables are equally important in the training of the networks. The universe of discourse ranges from -1 to 1 . Based on statistical techniques, the scale mapping is described by:

$V_{n}^{i}=\frac{V_{0}^{i}-\mu}{K \sigma}$

where $V_{n}^{i}$ represents the scaled input variable, $V_{0}^{i}$ stands for the input variable, $\mu$ the mean value of the input variable, $\sigma$ the standard deviation of the input variable and $K$ a constant gain and its value being 1.96. On the other hand, a scale mapping is also performed to transfer the range of values of output variables into corresponding real values. The scaling mapping is performed such that the maximum and minimum values of the output variables are mapped into the expected maximum and minimum values. The connection weights are adapted properly using the back-propagation learning algorithm [11], which uses a gradient-descent technique to minimize the summation of the squared error between the calculated output of the network and the desired output. Thus, the weights in the $n$th layer are modified by an amount $\Delta W_{j i}^{n}$ given by:

$\Delta W_{j i}^{n}(k)=-\eta \frac{\partial E}{\partial W_{j i}^{n}}+\alpha \Delta W_{j i}^{k}(k-1)$

where $E$ represents the squared error, $\eta$ the learning rate, $\alpha$ the momentum coefficient and $k$ the number of the current iteration. In a multi-layer neural network, the weights of the nodal connection are set and modified randomly. A large number of iterations are required to back-propagate the error until an acceptable error tolerance level is achieved through the training process. The training of the network is carried out off-line.

\section{Hardware set-up of the WEDM sparking frequency monitoring and control system}

Fig. 2 illustrates the hardware set-up of the WEDM sparking frequency monitoring and control system [12]. The system consists of a flushing-type WEDM machine,
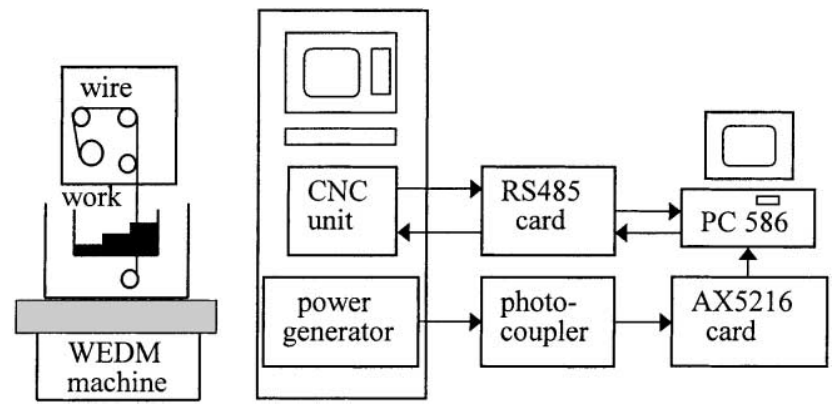

Fig. 2. Hardware set-up-of the WEDM sparking frequency monitoring and control system. 
a WEDM sparking frequency monitor (composed of a photocouple circuit and an AX5216 counter card), a PC computer and an interface card for communication between the PC and the CNC unit of the machine. The WEDM machine is a 5-axis CNC machine with transistor-controlled power generator. The power generator of the WEDM machine is composed of a low and a high power circuit, whilst a pulse generator is an iso-energy power supply system. Normal sparks and arc sparks can be discriminated by the pulse generator according to the ignition delay time and the voltage level of each spark. Based on the discrimination of gap status, the sparking time of normal sparks and arc sparks are controlled and specified by means of on-time and arc on-time settings, respectively. Similarly, the pulse intervals time of normal sparks and arc sparks are controlled by off- and arc off-time settings, respectively. The photocouple circuit is used to reduce the high frequency noise resulting from electromagnetic interference (EMI). By the AX5216 counter card, total sparks $\left(N_{\mathrm{t}}\right)$, normal sparks $\left(N_{\mathrm{n}}\right)$ and abnormal sparks $\left(N_{\mathrm{a}}\right)$ (composed of arc discharge and short circuit) in a specific time interval $(\Delta t)$ are detected. Thus, the total sparking frequency and the proportion of abnormal sparks can be computed as $N_{\mathrm{t}} / \Delta t$ and $N_{\mathrm{n}} / N_{\mathrm{t}}$, respectively. The discharge current of this power supply system has a triangular waveform with a current rise of $400 \mathrm{~A} / \mu \mathrm{s}$. The flushing pressure can be tuned by a hand valve. The adjustable parameters of this machine includes on-time, off-time, arc on-time, arc off-time, servo voltage, feed rate over-ride, wire speed and wire tension, and their working ranges being listed in Table 1. Servo voltage and feed rate over-ride settings represent the reference value and the servo gain of the gap voltage control system provided by this machine, respectively. Clearly, a higher value of servo gain may result in a fast response and unstable conditions. A PC/AT-586 is used for calculation and implementation of an learning algorithm and control strategy. The sampling interval is adjustable within the range $2-65535 \mathrm{~ms}$. A RS485 interface card is employed to handle the I/O (input/output) data and communicate with the CNC unit through an RS232 port. Through the interface, all controllable parameters including power settings and servo voltage can be updated and machining results including average gap voltage and real machining feed rate can be accessed in real-time.

Table 1

Adjustable parameters of the WEDM machine

\begin{tabular}{ll}
\hline Items & Range \\
\hline On-time & $0.1-0.9 \mu \mathrm{s}$ (9 steps) \\
Off-time & $8-50 \mu \mathrm{s}(43 \mathrm{steps})$ \\
Arc on-time & $0.1-0.5 \mu \mathrm{s}(5 \mathrm{steps})$ \\
Arc off-time & $9-50 \mu \mathrm{s}$ (42 steps) \\
Servo voltage & $30-70 \mathrm{~V}$ \\
Feed rate over-ride & $0-310 \%$ \\
Wire speed & $1-15 \mathrm{~mm} / \mathrm{min}(15 \mathrm{steps})$ \\
Wire tension & $500-2500$ gf $(15$ steps $)$ \\
\hline
\end{tabular}

\section{A feed-forward neural network for on-line estimation of the workpiece height}

In this section, an attempt at estimating the workpiece height of WEDM through an artificial neural network is reported. In order to obtain correct information for the input signals of the neural network and distinguish the machining condition, a few experiments have been carried out under the conditions of cutting a workpiece with a sudden increase and decrease in height. Fig. 3 shows the on-line recorded data with gap voltage control system when cutting a workpiece with a sudden increase in height. As shown in Fig. 3(a), the machining feed rate decreases with the increase of workpiece height. Since the average gap voltage is controlled at a pre-determined value by means of the servo feed function provided by the WEDM machine, an average ignition delay time approximately proportional to the average gap voltage can be maintained at a fixed level. Therefore, the total

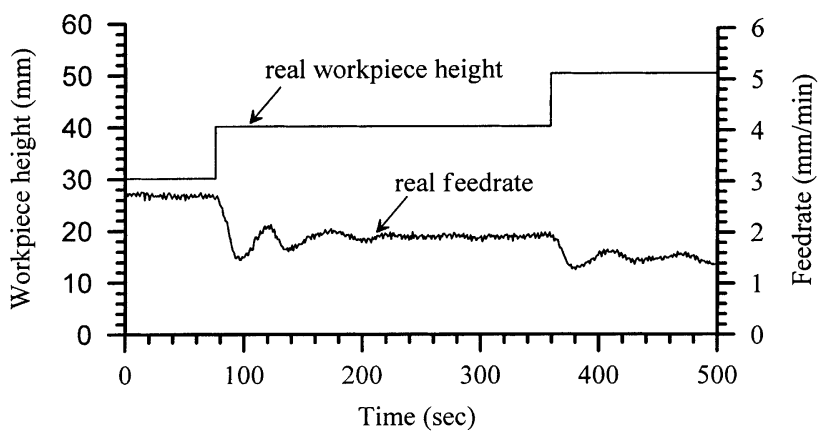

( a )

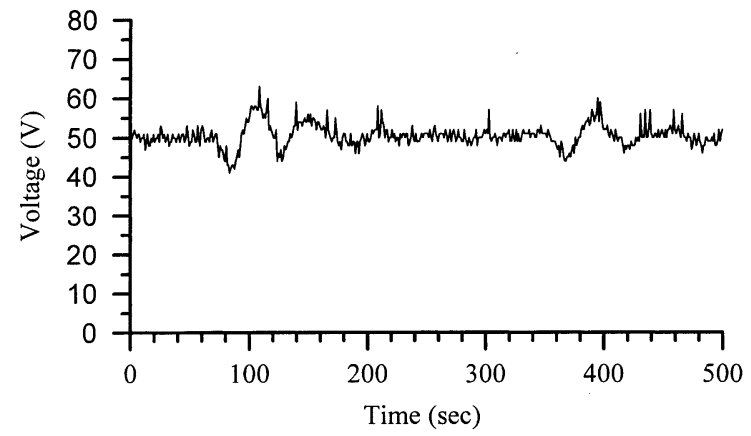

(b)

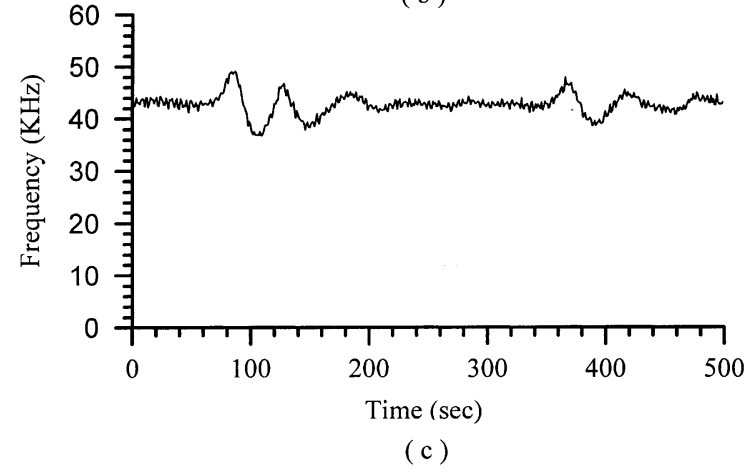

Fig. 3. (a) Real feed rate, (b) average gap voltage and (c) total sparking frequency with a gap voltage control system when cutting a workpiece with a sudden increase in height. 


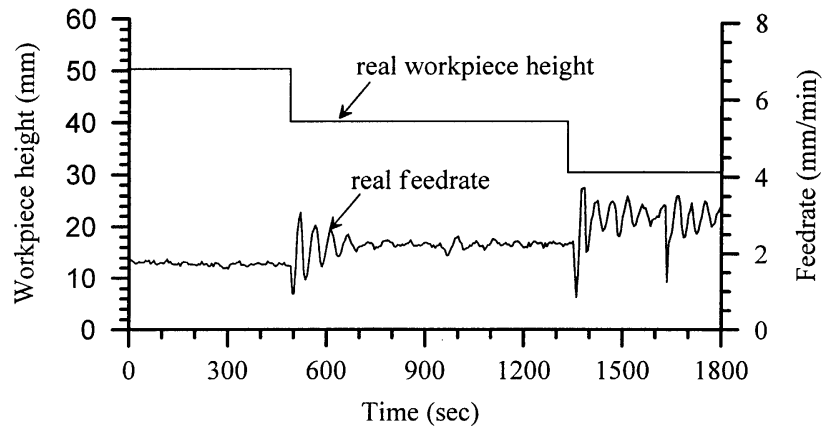

(a)

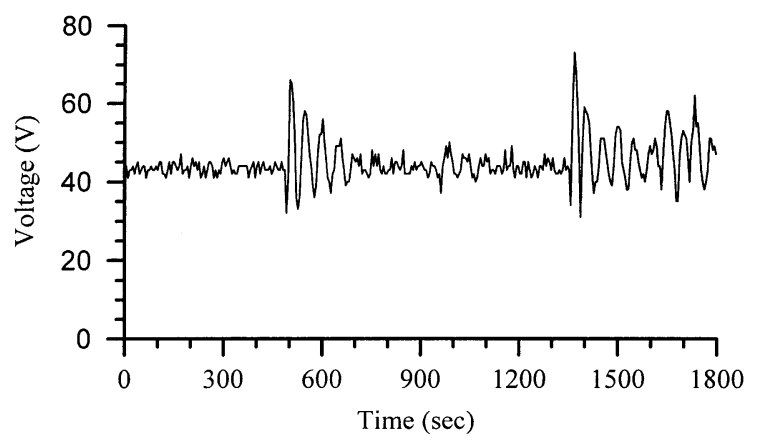

(b)

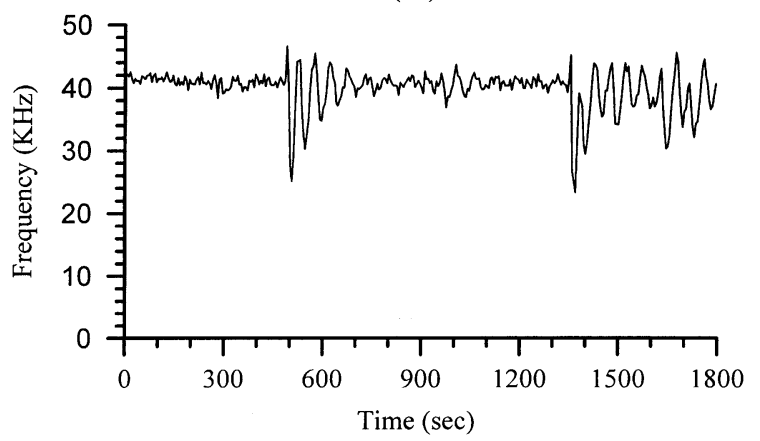

(c)

Fig. 4. (a) Real feed rate, (b) average gap voltage and (c) total sparking frequency with a gap voltage control system when cutting a workpiece with a sudden decrease in height.

sparking frequency determined by the average ignition delay time, the pule on-time and the pule off-time is kept at the same level, as illustrated in Fig. 3(c). Fig. 4 shows the online recorded data with gap voltage control system when cutting a workpiece with a sudden decrease in height. Fig. 4(a) demonstrates that the machining condition becomes unstable when the thickness of the workpiece changes suddenly. As shown in Fig. 4(b), the average gap voltage cannot be controlled at a fixed level when a workpiece of $30 \mathrm{~mm}$ height is machined. Thus, correct machining parameters should be set to suit the workpiece profile so as to avoid wire rupture and maintain stable machining.

In this study, the total sparking frequency, the normal sparking frequency, the arc sparking frequency, the abnormal ratio, the average gap voltage, the real feed rate, the variation of average gap voltage and the variation of the feed rate are employed as input signals for the input layer of the neurons. The variation of gap voltage is specified as the difference between the mean value of 10 successive sampling gap voltages and the current sampling gap voltage. Similarly, the variation of the feed rate is specified as the difference between the mean value of 10 successive sampling feed rates and the current sampling feed rate. The average gap voltage and real feed rate change drastically when the machining plate thickness is varied. Therefore, the variation of the average gap voltage and the variation of the feed rate can be used as the input signals of the neural network to distinguish a stable machining status between a transient machining status when machining a workpiece with variable height. Hence, the output layer of the neural networks has two nodes which represent the workpiece height and machining status. The estimated value of the machining status ranges between zero and unity. Target values of stable machining status and transient machining status are specified as zero and unity, respectively, during the training of the neural networks. The number of neurons in the hidden layer is determined by trial-and-error experimentation. To summarize, a feed-forward neural network of 8-9-2 type with back-propagation learning is adopted here to estimate the workpiece height and distinguish the machining condition. Fig. 5 presents a schematic diagram of the neural network for the estimation of the workpiece height.

\section{Experimental verification and analysis}

The developed neural network is implemented in a PC/AT using the $\mathrm{C}$ language. To evaluate the developed network, a number of WEDM experiments have been made under the conditions of cutting a workpiece with a sudden decrease and increase in height. Based on the on-line estimated workpiece height and the machining status of the gap condition, a rule-based strategy for adaptive parameters setting is proposed to maintain on stable machining and improve the machining efficiency. Estimation results of the developed network and experimental verification of the rulebased strategy are shown in the following.

Fig. 6 demonstrates the on-line estimation results of the neural network when cutting a workpiece with a sudden decrease in height. As shown in this figure, the average error of the workpiece height estimation is $1.2 \mathrm{~mm}$ and the response to changes in workpiece height is $16 \mathrm{~s}$. The machining status can respond also to the change of the average gap voltage and thus its value can reflect the machining condition. The nearer that the value of machining status approaches unity, the more unstable the gap condition becomes. Fig. 7 shows the on-line estimation results of the neural network when cutting a workpiece with a sudden increase in height. The developed network can correctly estimate the workpiece height with an average error of $1 \mathrm{~mm}$. The machining status also properly depicts the machining condition. 


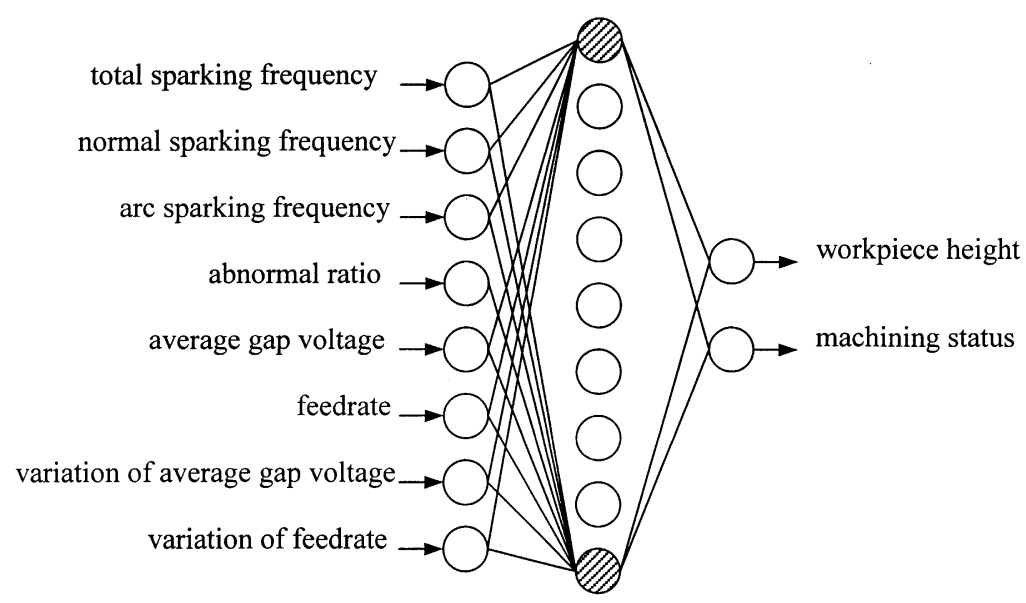

Fig. 5. Schematic diagram of the neural network for the estimation of the workpiece height.

Based on the on-line estimated workpiece height and the working status, a rule-based strategy is proposed to achieve optimal and stable machining. The rule-based strategy is designed according to the following: if the value of the machining status is higher than 0.8 , the off-time setting is increased by $6 \mu$ s to improve the machining condition. If the value of the machining status is lower than 0.4 , a look-up table for adaptive parameters setting is performed in response to the change in workpiece thickness. Table 2 depicts a look-up table for the adaptive parameters setting

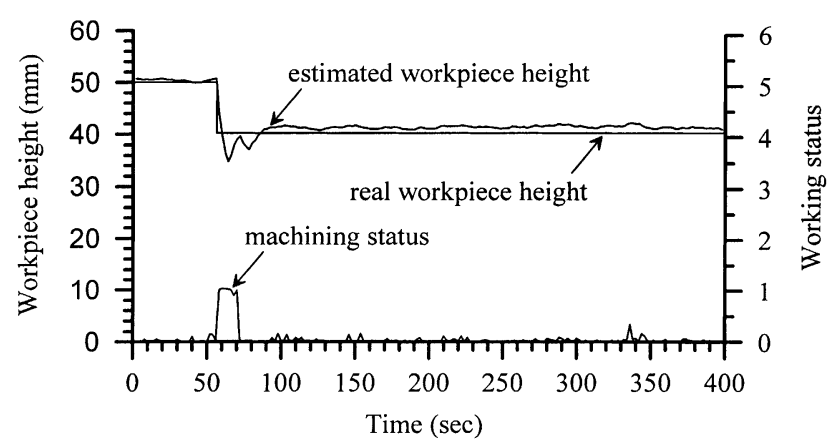

(a)

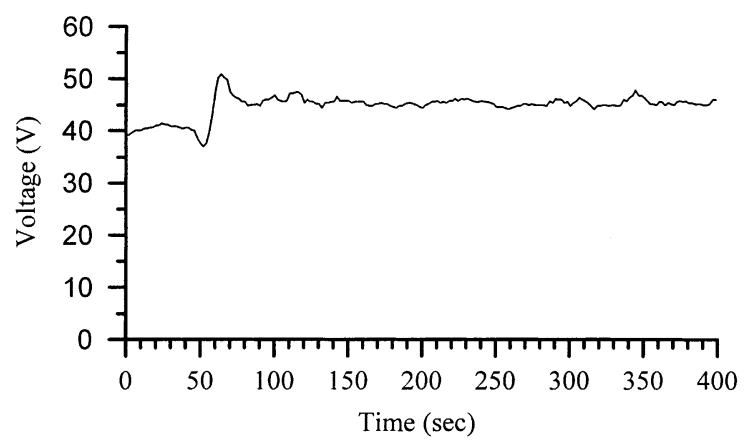

(b)

Fig. 6. On-line estimation results of the neural network when cutting a workpiece with a sudden decrease in height: (a) estimated workpiece height and working status; (b) average gap voltage. used in the experiments. Fig. 8 demonstrates the machining results with adaptive parameters setting when cutting a workpiece with a step decrease in height. According to the rule-based strategy, the servo voltage and power settings can be correctly adjusted to suit the workpiece profile. By comparing Fig. 3 with Fig. 8, the machining stability and machining efficiency can be improved greatly with the rulebased strategy. Fig. 9 shows the machining results with adaptive parameters setting when cutting a workpiece with a step increase in height. In comparison with Fig. 4, the

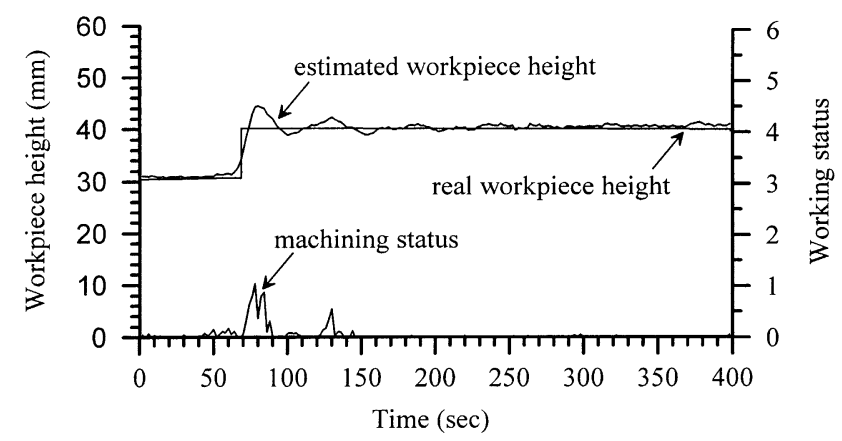

(a)

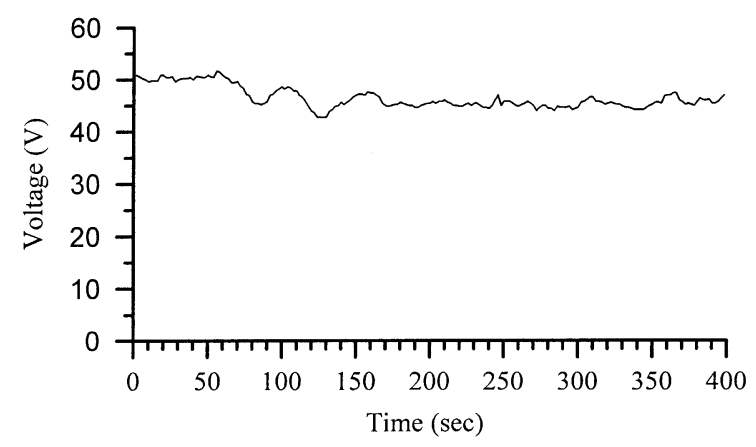

(b)

Fig. 7. On-line estimation results of the neural network when cutting a workpiece with a sudden increase in height: (a) estimated workpiece height and working status; (b) average gap voltage. 
Table 2

A look-up table for the adaptive parameters setting used in the experiments (workpiece: SKD11 tool steel; wire electrode: brass, $\phi 0.25 \mathrm{~mm}$; wire feed: $7 \mathrm{~m} /$ min; wire tension: $1000 \mathrm{gf}$; upper water pressure: $6.5 \mathrm{bar}$; lower water pressure: $11 \mathrm{bar}$ )

\begin{tabular}{llllll}
\hline Workpiece height $(\mathrm{mm})$ & On-time $(\mu \mathrm{s})$ & Off-time $(\mu \mathrm{s})$ & Arc on-time $(\mu \mathrm{s})$ & Arc off-time $(\mu \mathrm{s})$ & Servo voltage $(\mathrm{V})$ \\
\hline $28-33$ & 0.9 & 12 & 0.4 & 18 & 50 \\
$33-38$ & 0.9 & 12 & 0.4 & 18 & 48 \\
$38-43$ & 0.9 & 12 & 0.5 & 18 & 45 \\
$43-48$ & 0.9 & 12 & 0.5 & 18 & 42 \\
$48-53$ & 0.9 & 12 & & & 40 \\
\hline
\end{tabular}

developed system can automatically optimize machining even at difficult locations where the workpiece thickness changes suddenly.

In order to enhance the attractiveness for practical application, two approaches in applying the neural networks to the WEDM process are addressed. For the first approach, the

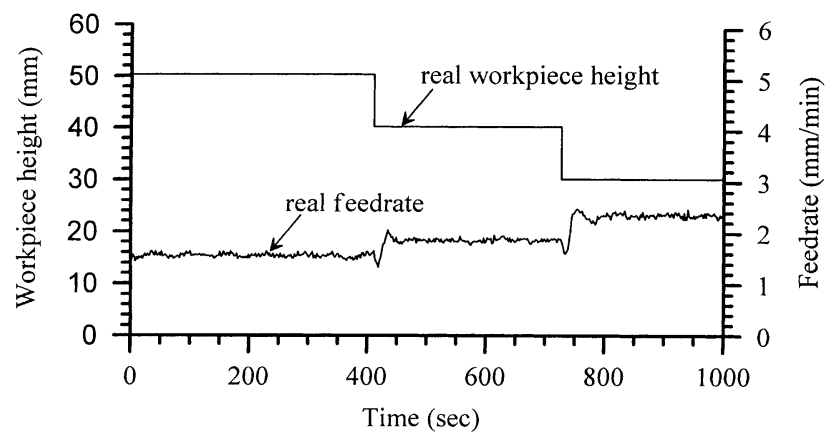

(a)

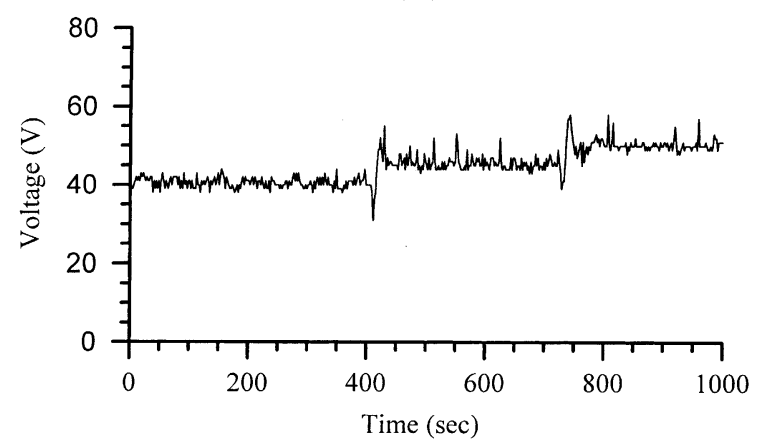

(b)

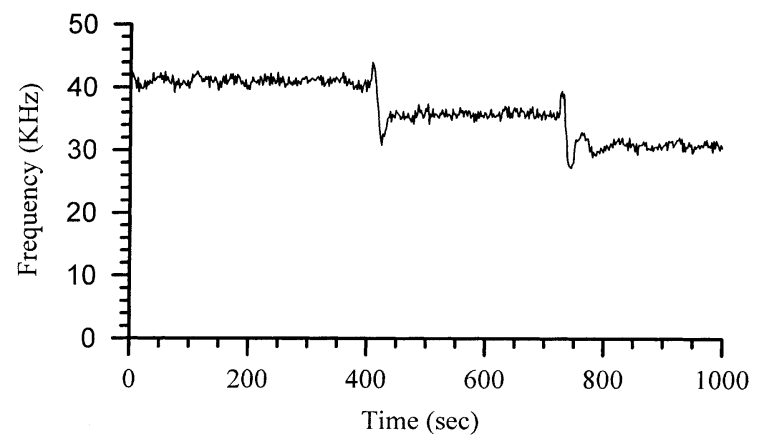

(c)

Fig. 8. (a) Real feed rate, (b) average gap voltage and (c) total sparking frequency with adaptive parameters setting when cutting a workpiece with a step decrease in height. neural networks are trained under constant power settings and the corresponding weighting factors are recorded and stored in a memory space. Thus, networks can be applied to different machining conditions through the memory-based weighting factors. For the second approach, the networks have power condition information by incorporating power

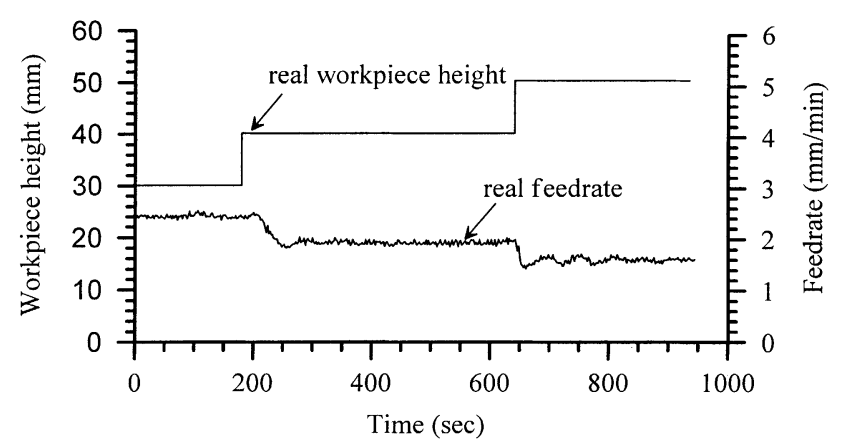

(a)

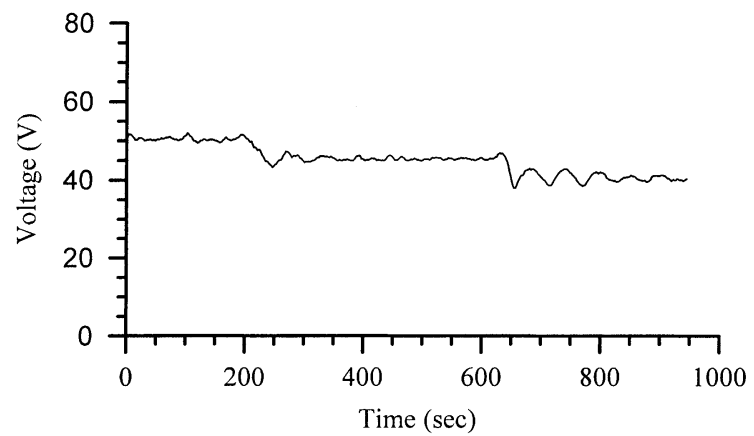

(b)

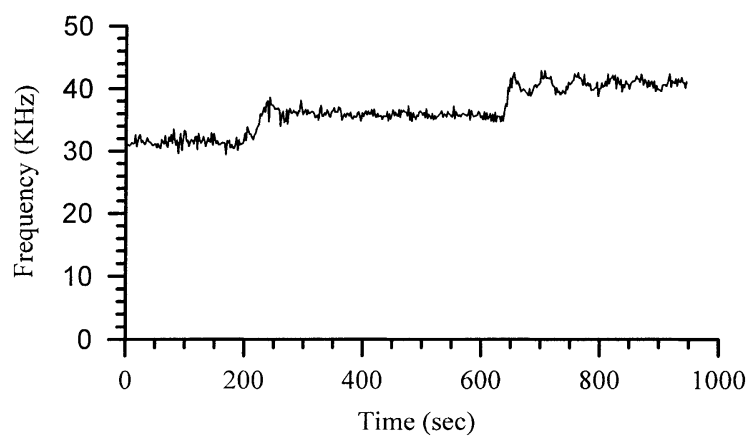

(c)

Fig. 9. (a) Real feed rate, (b) average gap voltage and (c) total sparking frequency with adaptive parameters setting when cutting a workpiece with a step increase in height. 
settings as input signals. Since the process parameters are incorporated into the learning process, the networks are expected to operate well for a wide variety of machining conditions.

\section{Conclusions}

This paper describes a neural network approach for the on-line estimation of the workpiece height in WEDM. A feed-forward neural network with back-propagation learning algorithm is used to construct the on-line estimation model. The developed network can successfully estimate the workpiece height with an accuracy of $1.6 \mathrm{~mm}$. Based on the on-line estimated workpiece height, a rule-based strategy for adaptive parameters setting is proposed to maintain a stable machining and improve the machining efficiency.

\section{References}

[1] H. Obara, Wire-cut electrical discharge machine, US Patent $4,510,367$ (1985)
[2] Y. Nakayama, Wire electrical discharge machine and method of use thereof, US Patent 5,243,166 (1993).

[3] Y. Ishibashi, A. Komori, Wire electric discharge machine having alterable discharge period, US Patent 5,362,936 (1994).

[4] K.P. Rajurkar, W.M. Wang, J.A. McGeough, WEDM identification and adaptive control for variable height components, Ann. CIRP 43 (1) (1994) 199-202.

[5] K.P. Rajurkar, W.M. Wang, W.S. Zhao, WEDM-adaptive control with a multiple input model for identification of workpiece height, Ann. CIRP 46 (1) (1997) 147-150.

[6] J. Prohaszka, A step toward intelligent manufacturing: modeling and monitoring of manufacturing processes through artificial neural networks, Ann. CIRP 42 (1) (1993) 485-488.

[7] R. Teti, S.R.T. Kumara, Intelligent computing methods for manufacturing systems, Ann. CIRP 46 (2) (1997) 629-652.

[8] T.A. Spedding, Z.Q. Wang, Study on modeling of wire EDM process, J. Mater. Process. Technol. 69 (1997) 18-28.

[9] T.A. Spedding, Z.Q. Wang, Parametric optimization and surface characterization of wire electrical discharge machining process, Prec. Eng. 20 (1) (1997) 5-15.

[10] J.Y. Kao, Y.S. Tarng, A neural-network approach for the on-line monitoring of the electrical discharge machining process, J. Mater. Process. Technol. 69 (1997) 112-119.

[11] J.M. Zurada, Introduction to Artificial Neural Systems, West Publishing Company, 1992.

[12] M.T. Yan, Y.S. Liao, Adaptive control of WEDM process using the fuzzy control strategy, J. Manuf. Syst. 17 (4) (1998) 263-274. 